\title{
An Observational Estimate of Volume and Freshwater Flux Leaving the Arctic Ocean through Nares Strait
}

\author{
ANDREAS MÜNCHOW \\ College of Marine and Earth Studies, University of Delaware, Newark, Delaware \\ Humfrey Melling \\ Institute of Ocean Sciences, Sidney, British Columbia, Canada \\ KeLLy K. FALKNER \\ College of Oceanic and Atmospheric Sciences, Oregon State University, Corvallis, Oregon
}

(Manuscript received 20 September 2005, in final form 10 April 2006)

\begin{abstract}
The Arctic Ocean is an important link in the global hydrological cycle, storing freshwater and releasing it to the North Atlantic Ocean in a variable fashion as pack ice and freshened seawater. An unknown fraction of this return flow passes through Nares Strait between northern Canada and Greenland. Surveys of ocean current and salinity in Nares Strait were completed in the summer of 2003. High-resolution data acquired by ship-based acoustic Doppler current profiler and via hydrographic casts revealed subtidal volume and freshwater fluxes of $0.8 \pm 0.3 \mathrm{~Sv}$ and $-25 \pm 12 \mathrm{mSv}\left(\mathrm{Sv}=10^{3} \mathrm{mSv}=10^{6} \mathrm{~m}^{3} \mathrm{~s}^{-1}\right)$, respectively. The observations resolved the dominant spatial scale of variability, the internal Rossby radius of deformation $\left(L_{D} \sim 9 \mathrm{~km}\right)$, and revealed a complex, yet coherent along-channel flow with a Rossby number of about 0.13 , close to geostrophic balance. Approximately one-third of the total volume flux was associated with across-channel slope of the sea surface and two-thirds (68\%) with across-channel slope of isopycnal surfaces. During the period of observation, sustained wind from the southwest weakened the average downchannel flow at the surface. The speed of tidal currents exceeded subtidal components by a factor of 2 . Tidal signals were resolved and removed from the observations here using two independent methods resolving horizontal and vertical variability of tidal properties, respectively. Tidal current predictions from a barotropic model agreed well with depth-averaged observations in both amplitude and phase. However, because estimates of freshwater flux require accurate surface currents (and salinity), a least squares fitting procedure using velocity data was judged more reliable, since it permits quantification of vertical tidal current variations.
\end{abstract}

\section{Introduction}

The Arctic Ocean plays a pivotal role in the global hydrological cycle by returning freshwater, in the form of freshened seawater and ice, to the North Atlantic Ocean through Fram Strait and the passages of the Canadian Archipelago (Aagaard and Carmack 1989). Spatial and temporal variability in the delivery of the freshwater potentially impacts the formation of deepwater in

Corresponding author address: Andreas Münchow, College of Marine and Earth Studies, University of Delaware, Newark, DE 19716.

E-mail: muenchow@udel.edu the North Atlantic, the global thermohaline circulation and climate. Over the past decade it has become clear that factors affecting the global freshwater cycle have changed (Dickson et al. 2002, 2003; Munk 2003; Serreze et al. 2000; Curry et al. 2003) and that resulting signals are propagating through the North Atlantic (Dickson et al. 1988; Belkin et al. 1998). Despite their potential impacts and global importance, freshwater fluxes from the Arctic to the North Atlantic are nearly unknown since direct observations are rare (e.g., Fram Strait: Schauer et al. 2004; Barents Sea: Ingvalsen et al. 2004) or inadequate (e.g., Canadian Archipelago: Melling 2000).

The release of freshwater from a reservoir profoundly impacts the dynamics of the receiving basin. Freshwater discharges into the ocean are associated 
with lateral differences in density and thus in pressure, which in turn induce currents termed buoyancy-driven or thermohaline by the coastal and deep-ocean communities, respectively. Rossby (1937) first realized that the steady state that results from two contacting fluids with different densities initially at rest on a rotating earth, can be predicted via arguments based on vorticity. From his theory, the Rossby radius of deformation emerges as a fundamental spatial scale of motion (Gill 1982). The width of a baroclinic flow in geostrophic balance in a density stratified fluid scales with the Rossby radius. At high latitudes and in shallow water this scale is quite small, about $5-10 \mathrm{~km}$.

For the present discussion, we view the Arctic Ocean as a reservoir of low salinity water maintained by massive river discharges from Siberia (Lena, Ob, Yenesei) and North America (Yukon and Mackenzie), by local precipitation, by sea ice meltwater and by the inflow of relatively freshwater from the Pacific Ocean via Bering Strait (Woodgate and Aagaard 2005). The Arctic Ocean connects to the North Atlantic via the wide straits between Greenland and Europe (Fram Strait, Svalbard-Franz-Josef Passage) and a network of narrow straits within the Canadian Archipelago (Fig. 1). The geographical terms wide and narrow are misleading from a dynamical perspective, since both the 300$\mathrm{km}$-wide Fram Strait and the 35-km-wide Nares Strait to the west of Greenland are dynamically wide: the internal Rossby radius of deformation is much less than the channel width in both cases. The freshwater fluxes from the Arctic and Nordic Seas potentially contribute to the vertical density stratification in the deep convection regions of the Labrador (Pickart et al. 2002), Greenland (Ronski and Budéus 2005), and Irminger Seas (Pickart et al. 2003), but the mechanisms by which low-density shelf waters enter the basins to influence density stratification in regions of deep convection remain uncertain even though intriguing phenomena are emerging (Pickart et al. 2005; Lozier and Reed 2005).

Davis Strait connects the seasonally ice covered Baffin Bay with the largely ice free Labrador Sea. Cuny et al. (2005) have examined data from moored instruments and hydrographic surveys to estimate the fluxes of volume and freshwater through Davis Strait. Their calculation of a net southward flux is consistent with earlier hydrographic surveys (LeBlond et al. 1981; Smith et al. 1937), which indicated that surface waters from Baffin Bay and the Arctic Ocean move southward on the Labrador shelf and contribute substantially to the buoyancy of the Labrador Current (Khatiwala et al. 1999). Moreover, Zweng and Münchow (2006) have found a significant decrease over time in salinity $\left[-0.05 \pm 0.03(10 \mathrm{yr})^{-1}\right]$ in waters beneath the surface layer between southern Nares Strait at $80^{\circ} \mathrm{N}$ and northern Labrador at $64^{\circ} \mathrm{N}$. Because there has been no freshening at depth or within the deep basin of Baffin Bay, the freshening along Baffin Island must be indicative of a stronger southward buoyancy-driven geostrophic circulation via baroclinic adjustment. The export of fresher Arctic waters through Davis Strait into the Labrador Sea may well have increased over the same period.

Nares Strait separates Greenland and Ellesmere Island between latitudes of $78^{\circ}$ and $82^{\circ} \mathrm{N}$ (Fig. 1) and stretches $530 \mathrm{~km}$ between the Lincoln Sea in the north and Baffin Bay in the south. The components of Nares Strait from north to south include Robeson Channel, Hall Basin, Kennedy Channel, Kane Basin, and Smith Sound (Fig. 1b). There is a sill in Kane Basin at about $220 \mathrm{~m}$ depth that separates northern and southern sections where depth ranges between 300 and $600 \mathrm{~m}$. On adjacent land, mountains rise to above 1000-m elevation on both sides of the strait. Pack ice and icebergs are continually present even during summer, as illustrated by Fig. 2 for 2003, when ice coverage was actually unusually light; breakup occurred in mid-July and ice-free area was greatest in mid-August. Nares Strait is a pathway for the southward flow of Arctic water and ice (Samelson et al. 2006; Kwok 2006). A dramatic illustration occurred during 1962-64, when the $20 \mathrm{~km} \times 10 \mathrm{~km}$ ice island WH-5 drifted from the Lincoln Sea via Nares Strait into the Labrador Sea (Nutt 1966).

Sadler (1976) and Bourke et al. (1989) present hydrographic observations from summer expeditions to Nares Strait in 1971 and 1986; there are no well-resolved cross sections of the flow. The only direct observations of current were acquired by meters at three locations in Robeson Channel over a 6-week period in 1972 and published by Sadler (1976). From these sparse data, Sadler (1976) estimates a mean southward volume flux of $0.7 \mathrm{~Sv}\left(1 \mathrm{~Sv} \equiv 10^{6} \mathrm{~m}^{3} \mathrm{~s}^{-1}\right)$; we note that more than $50 \%$ of this flux is associated with the unusually strong current recorded by a single instrument at 100-m depth and $5 \mathrm{~km}$ from Ellesmere Island.

FIG. 1. Maps of the study area: (a) Northern Hemisphere, and (b) Nares Strait, where the rectangle indicates the Kennedy Channel $\mathrm{ADCP} / \mathrm{CTD}$ section and the "+" symbol indicates location of the 220-m sill. Contours are bathymetry with intervals of 1000-3000 $\mathrm{m}$ in (a) and 250-1000 $\mathrm{m}$ in (b). 

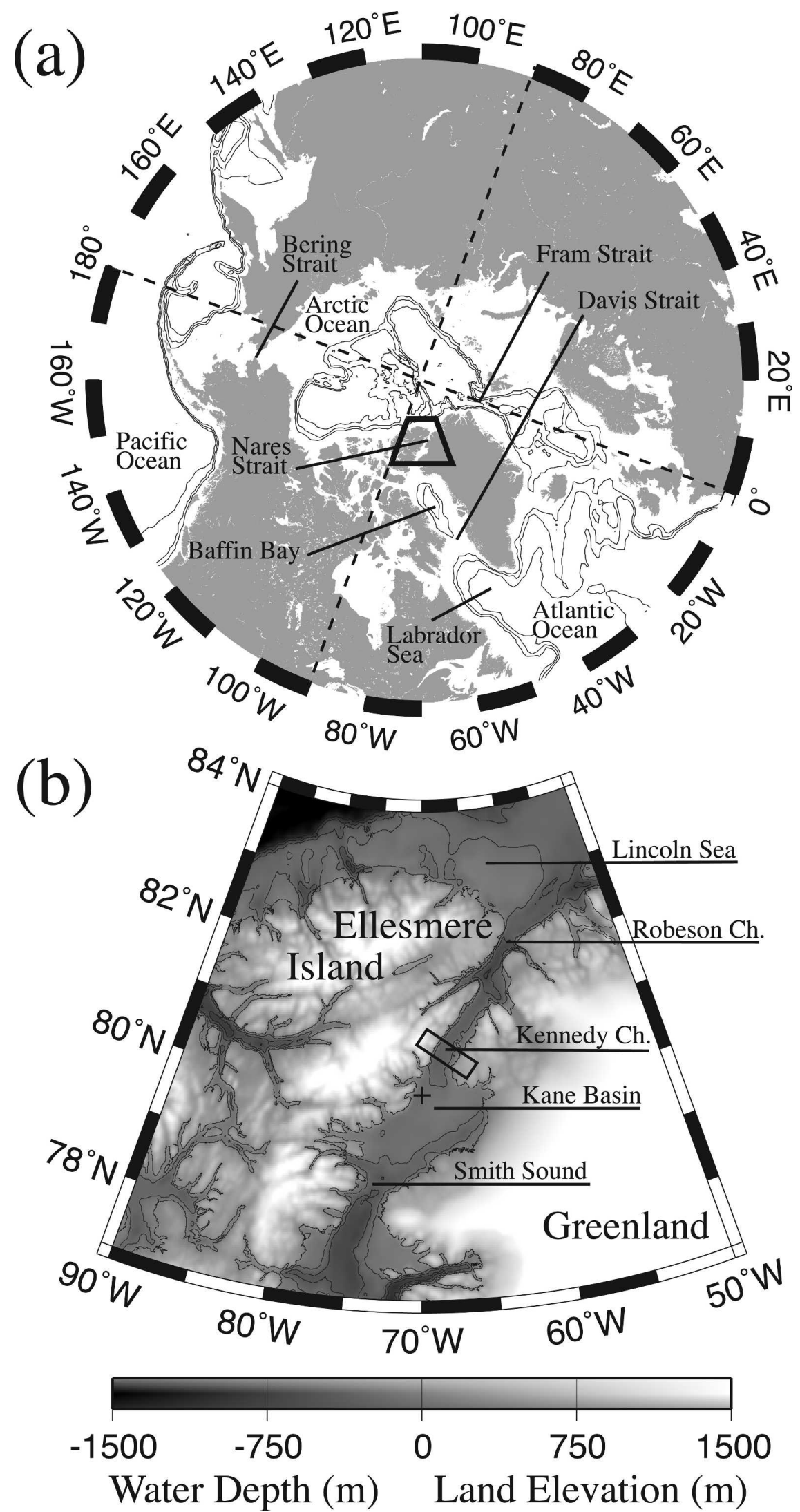

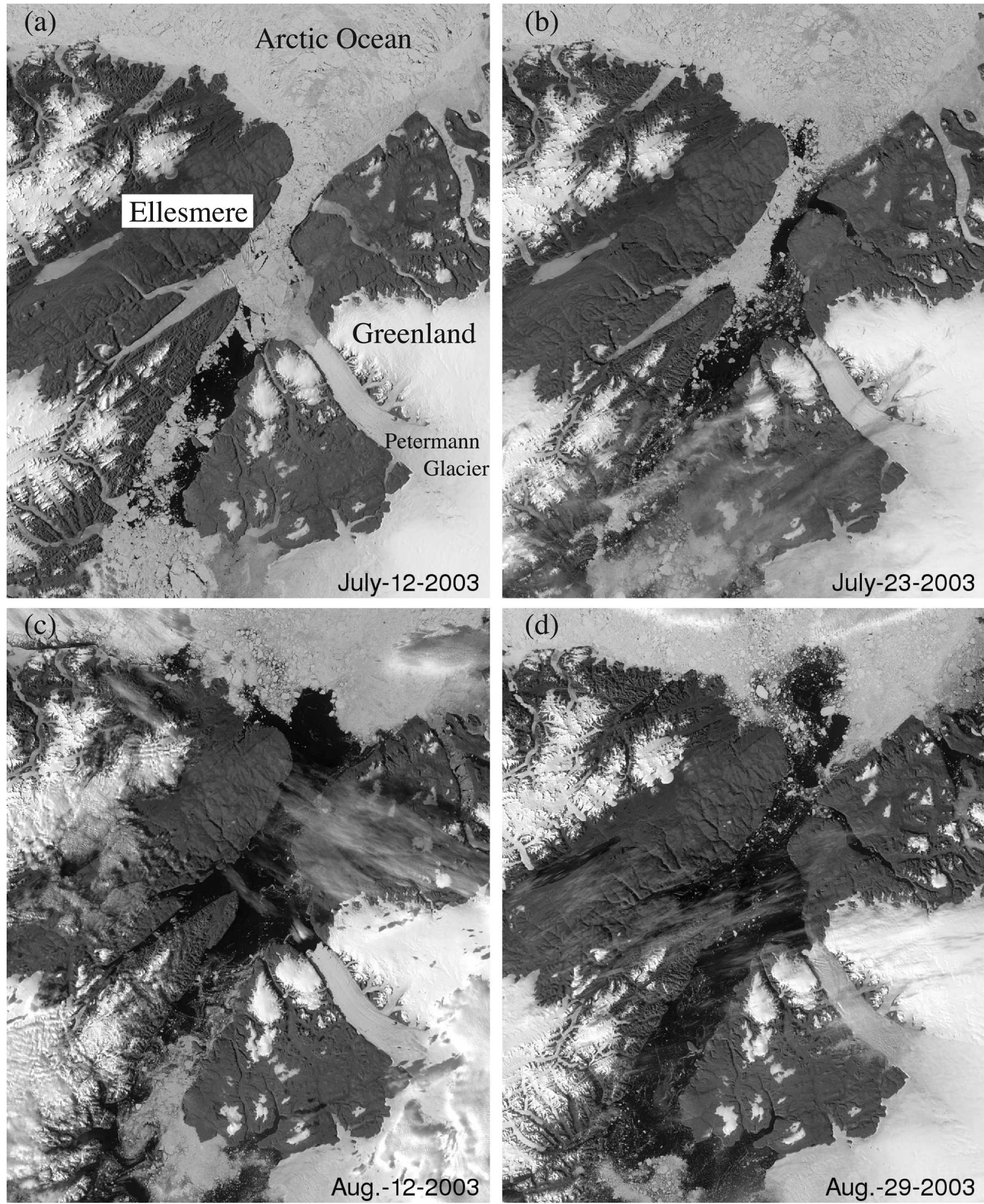

FIG. 2. MODIS images of Kennedy and Robeson Channels during July-August 2003. The USCGC Healy operated in the area from 3 to 12 Aug 2003. Black, gray, and white areas are open water, land, and ice, respectively. Almost transparent white features are clouds. (Images courtesy of MODIS Rapid Response Project at NASA/GSFC.) 
In the following sections we present an estimate of the fluxes of volume and freshwater through Nares Strait, based on synoptic observations of the velocity and salinity fields. The time scale of our surveys is measured in days; that is, we resolved tidal variability in the velocity field, but our observations serve as a snapshot with regard to monthly, seasonal, and interannual variability. The observations of both the velocity and density fields resolve variation of fields on the fundamental internal Rossby scale. Hence we are able to examine the spatial structure of the flow and to estimate fluxes without resorting to the common practice of linear interpolation between widely spaced sites of measurement. We describe methods, sensors, and calibrations in section 2, followed by a discussion of the hydrographic cross section and its implication for geostrophically balanced flow across the Nares Strait in section 3. Section 4 introduces the tidally dominated velocity observations and presents two independent methods for removing tidal currents from the record. The volume and freshwater fluxes, their scale of variability, and estimates of uncertainty are discussed in section 5 . We note that flux estimates of climatological relevance can only be derived from comparable observations of long duration. An array of recording instruments to facilitate such estimates is presently moored in Nares Strait.

\section{Data sources and methods}

The USCGC Healy visited the area between northern Canada and Greenland in the summer of 2003 to deploy oceanographic moorings and complete surveys of the velocity and hydrographic fields (see Fig. 1 for locations). A sequence of Moderate Resolution Imaging Spectroradiometer (MODIS) images (Fig. 2) reveals the evolving ice cover during July and August. The ship was north of Kane Basin during 3-12 August. The scene for 12 August in Fig. 2 is typical of the ice conditions encountered.

The Healy was outfitted with hull-mounted ADCP to measure current profiles, swath-scanning sonar to map the seafloor, and thermosalinograph for continuous measurement of near-surface temperature and salinity. We used a conductivity-temperature-depth (CTD) probe and rosette sampling system to profile water properties at specific stations. Meteorological sensors measured wind speed and direction, air temperature, and humidity. The instruments used for this study were the $75-\mathrm{kHz}$ phased array ADCP (Ocean Surveyor of $\mathrm{RD}$ Instruments) and the CTD probe on the rosette sampler (SBE9 + of Sea Bird Electronics). The CTD probe carried duplicate conductivity (model SBE-4C) and temperature (model SBE-3+) sensors calibrated by the manufacturer in May 2003 and a Paroscientific Digiquartz pressure sensor calibrated by the manufacturer in 2001. The salinities of seawater samples were determined on the vessel using a Guildline Autosal salinometer (model 8400B) operated in a temperaturecontrolled chamber and calibrated against standard seawater. Salinity measurements are accurate and precise to \pm 0.002 on the practical salinity scale (psu).

The ADCP transducer was mounted in a well filled with antifreeze solution and separated from the sea by an acoustic window. The ADCP detects the Doppler shift in sound backscattered from the water column, which is processed to yield a vertical profile of velocity relative to the moving ship. The profile of ocean current is obtained by subtracting the vessel's motion vector, which is derived from an independent bottom-tracking pulse. On the Healy, an Ashtech ADU2-3D GPS unit provided heading, pitch, and roll information needed to transform velocity profiles from ship-referenced to earth-referenced coordinates. Data from a P-code Trimble Centurion GPS provided accurate position for the velocity profiles. The ADCP velocity data presented here are the first of their kind originating from the USCGC Healy and are calibrated using the bottomtracking capability of the instrument with militarygrade p-code GPS data for both the horizontal (heading misalignment; e.g., Joyce 1989) and vertical planes of rotation (pitch and roll misalignment). No independent verification or cross-calibration with data from another vessel and/or installation is available; however, the favorable comparison (presented below) of tidal currents from the Healy ADCP system and independent numerical model predictions is probably the best verification of both model and USCGC Healy's ADCP system.

Hummon and Firing (2003) describe salient aspects of the relatively new phased-array ADCP technology used on the Healy. They compare data from the novel $75-\mathrm{kHz}$ system with that from a conventional $153-\mathrm{kHz}$ narrow-band ADCP. The transducer of the $75-\mathrm{kHz}$ four-beam phased-array ADCP is a grid of many small transducers arranged on a flat plate and controlled by software to project four collimated beams of sound into the water column. Either a coded broadband pulse and/ or an uncoded narrowband pulse can be transmitted. To achieve maximal depth penetration and minimal ringing in our application, we transmitted a 15-m-long narrow-band pulse and received echoes from ranges beyond a $10-\mathrm{m}$ blanking zone adjacent to the transducer. We recorded data separately for each ping and each beam without averaging. Because beams are directed obliquely, velocity cannot be measured in the lowest $15 \%$ of the water column where there is interference from a bottom echo received via beam 
sidelobes. Also, we lack data for the uppermost $18 \mathrm{~m}$ because the hull-mounted transducer was $8 \mathrm{~m}$ below the surface and signals from the first $10 \mathrm{~m}$ of range were obscured by ring-down of the transmitter.

We focus on a single $36-\mathrm{km}$ section between Ellesmere Island and Greenland at $80.5^{\circ} \mathrm{N}$ (Fig. 1) that we profiled repeatedly over several tidal cycles. Figure $3 \mathrm{a}$ indicates the data distribution in space along with our coordinate system rotated $36^{\circ}$ clockwise from true east and north to correspond to across- and along-channel directions, respectively. Data locations are projected onto the $x$ axis and subsequently presented as distances from the coast off Ellesmere Island. Figure $3 \mathrm{c}$ then indicates the data distribution in space along the transect and thus illustrates how and when we profiled the section. Within about $48 \mathrm{~h}$ we crossed the main channel (see Fig. 3b for the bottom profile) 10 times; however, the crossings varied in length from the full $36 \mathrm{~km}$ (crossing 2; from hour 532 to hour 538) to shorter but more rapid crossings (crossings 4-8; from hour 548 to hour 554). While this time-space sampling does not reflect ideal experimental design of tidally dominated channel flows, it constitutes a compromise to resolve both temporal (mostly tidal) and spatial (mostly subtidal) variability in the velocity field.

Figure 4 shows a composite of the depth-averaged ADCP velocity vectors after we removed barotropic tidal currents predicted by the numerical model of Padman and Erofeeva (2004) and averaged data into 2-km across-channel bins. The generally southward alongchannel flow becomes apparent; however, it exhibits much directional variability off Greenland. While we cannot exclude the possibility of eddy motions off Greenland, we are more inclined to believe this to be unresolved noise as the Greenland portion of the section was profiled less frequently than the Ellesmere side, such as in Fig. 3.

Figures 3 and 4 also indicate the location of nine CTD casts that we collected at eight stations over $25 \mathrm{~h}$ beginning late on 4 August (from hour 540 to hour $565)$, which do not resolve tidal variability. To estimating a potential error, we used underway thermosalinograph data from an intake about $7 \mathrm{~m}$ below the sea surface and found across- and along-channel surface salinity gradients of about $0.1 \times 10^{-4}$ and $0.2 \times 10^{-4}$ $\mathrm{m}^{-1}$, respectively (not shown). For a $0.3 \mathrm{~m} \mathrm{~s}^{-1}$ alongchannel and a $0.03 \mathrm{~m} \mathrm{~s}^{-1}$ across-channel tidal current amplitude (discussed below) maximum tidal displacements $U \times T / \pi$ are about 13 and $1.3 \mathrm{~km}$ where $U$ and $T$ are semidiurnal tidal current amplitude and periodicity. The tidal advection of the surface salinity gradients thus introduces a potential error with an upper limit of 0.2 and 0.01 salinity units for along- and across-

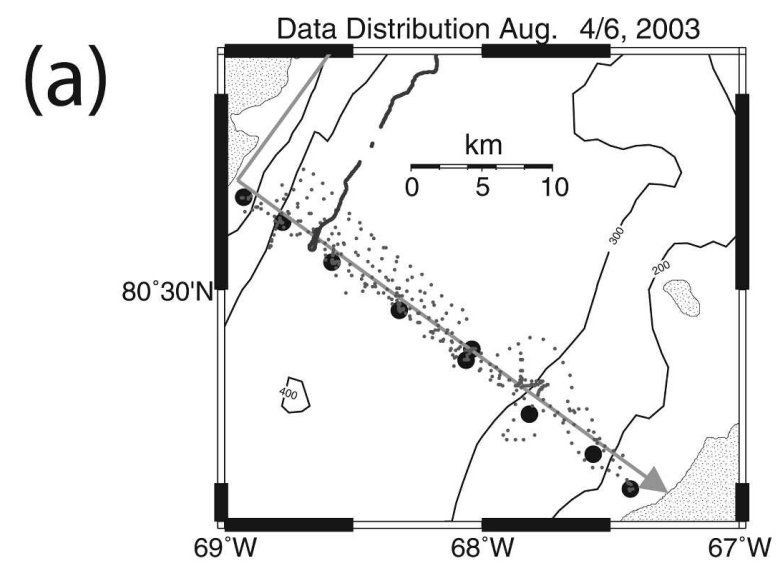

(b)
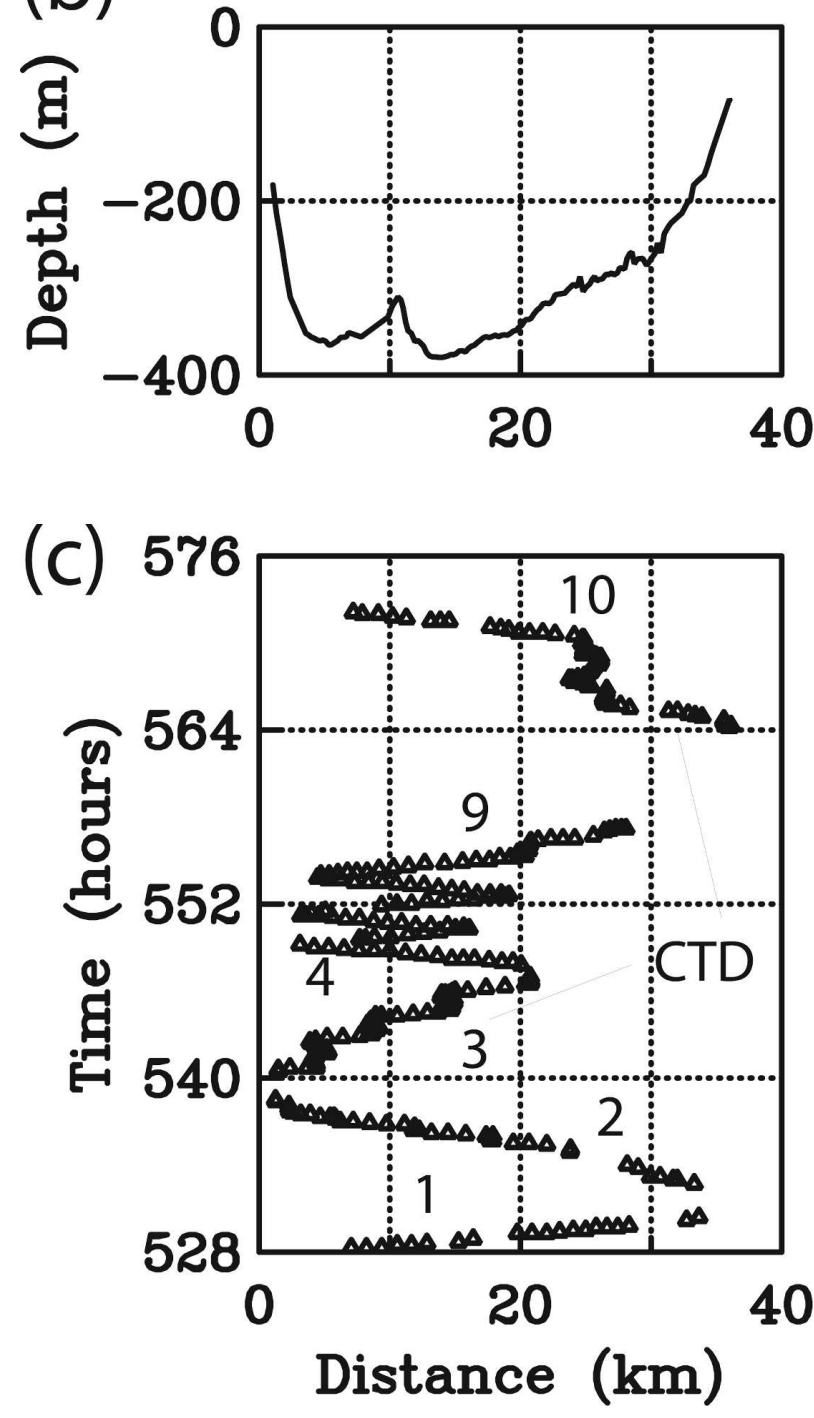

FIG. 3. Data distributions (a) in horizontal space (large filled circles are CTD, light dots are ADCP profile, and thick lines are thermosalinograph data locations), (b) bottom depth profile (composite), and (c) in time-space as across-channel distance and time (numbers indicate partial transect repetitions). 
Depth Averaged Currents Aug. 4/6, 2003

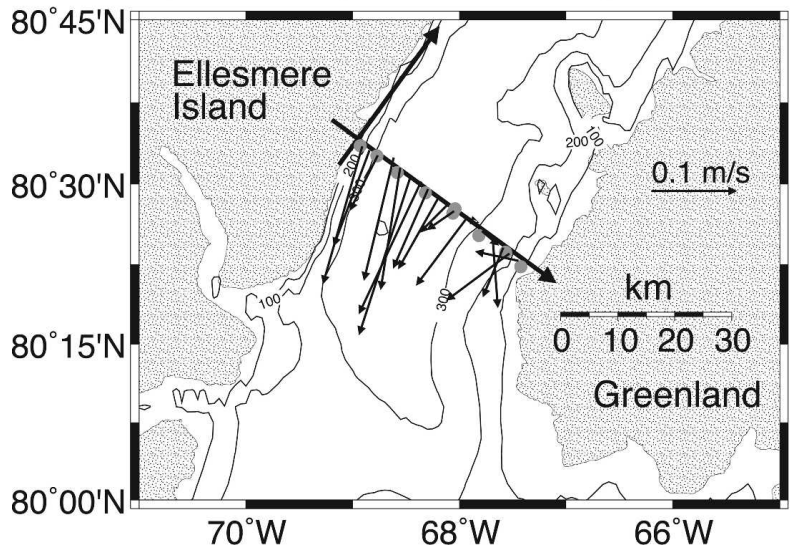

FIG. 4. Map of southern Kennedy Channel with location of CTD casts (gray circles), the coordinate system rotated $36^{\circ}$ clockwise from true east, and depth-averaged ADCP current vectors. The vectors represent a 2-day snapshot of detided flows.

channel gradients that, we speculate, are caused mainly by local melting of sea ice patches.

\section{Hydrography and geostrophic flow}

The seafloor slopes steeply down to 350-m depth within $4 \mathrm{~km}$ of Ellesmere Island but rises more gently toward Greenland in the east. Figures 5 and 6 display the temperature-salinity $(T-S)$ correlation and temperature, salinity and density sections, respectively. In the former we incorporate comparative data from the northern (Lincoln Sea) and southern (Baffin Bay) ends of Nares Strait collected in April and July of 2003, respectively. The $T-S$ correlation within Kennedy Channel was clearly different from either end of Nares Strait (Fig. 5). Features in Baffin Bay, the temperature maximum near 34.5 and near-freezing waters at 33.5 were absent. Near the bottom of Kennedy Channel, the $T-S$ correlation converged on that in the Lincoln Sea (Falkner et al. 2005). The ultimate origin of these waters is the Atlantic inflow to the Arctic through Fram Strait and through the Barents Sea (Woodgate et al. 2001), but their properties have evolved during a long cyclonic circuit around the margin of the Arctic basin (Melling et al. 1984). Scatter in the $T-S$ correlation in Kennedy Channel at all salinities is indicative of more active modification of waters than in the deeper basins to the north and south. In the strait, our observations revealed strong currents at tidal and subtidal frequencies and strong shear in both horizontal and vertical directions.

The surface layer in Kennedy Channel was quite variable in thickness and stratification; it was rarely well mixed to greater than $10-\mathrm{m}$ depth, and in some

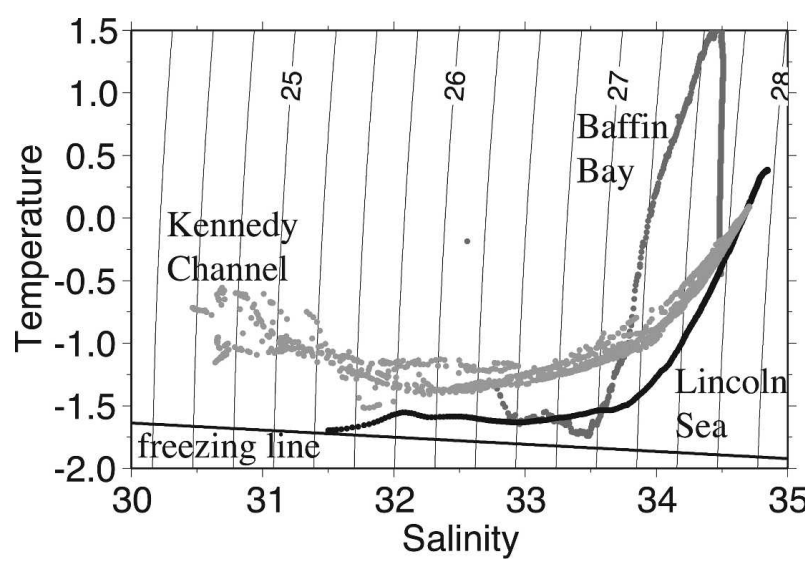

FIG. 5. The $T-S$ diagram with density contours and freezingtemperature line. The light gray symbols are from eight stations in Kennedy Channel while black and dark gray symbols represent data from the Lincoln Sea in the Arctic Ocean to the north and Baffin Bay to the south, respectively. All data were collected in 2003.

places was stratified to the surface (at such depths, possible disturbance by the ship cannot be ruled out). Below 10-m depth was a strongly stratified layer roughly 50-m thick, with salinity increasing from 30 to 33 (Fig. 6). This layer was the coolest in the water column, with temperature between $-1.2^{\circ} \mathrm{C}$ and $-1.4^{\circ} \mathrm{C}$, several tenths of a degree above freezing. Since the surface salinity is lower than for source waters at either end of the channel, this layer is likely the result of local admixture of ice-melt water. The warmest water was at the seafloor, 360-m deep at the center of this section. This water clearly came from the Lincoln Sea, since it is saltier and denser than any water in Baffin Bay. Moreover, the sill at $220 \mathrm{~m}$ depth in Kane Basin blocks inflow of all but low salinity water from the south (Fig. 1b). The highest salinity on this section, 34.71 , occurred at the seabed about halfway across the channel. However, water of salinity 34.65 was observed near the Greenland coast at about $150 \mathrm{~m}$ depth, $70 \mathrm{~m}$ shallower than the sill. If this water were to pass south over the sill, it could be a plausible contributor, albeit a little warm, to deep water of salinity 34.5 (Bourke et al. 1989) in Baffin Bay.

A notable feature of the salinity and density sections is the spreading of the isopycnals at about 130-m depth within $10 \mathrm{~km}$ of Ellesmere Island (Fig. 6). Isopycnal surfaces above this depth (e.g., $27.0 \mathrm{~kg} \mathrm{~m}^{-3}$ ) sloped upward toward the coast and those below it (e.g., 27.5 $\mathrm{kg} \mathrm{m}^{-3}$ ) sloped downward. A weaker feature of similar scale is evident near the Greenland coast. The appropriate internal Rossby radius,

$$
L_{D} \sim\left(g D \Delta \rho / \rho_{0}\right)^{1 / 2} / f \sim 9.6 \mathrm{~km} .
$$



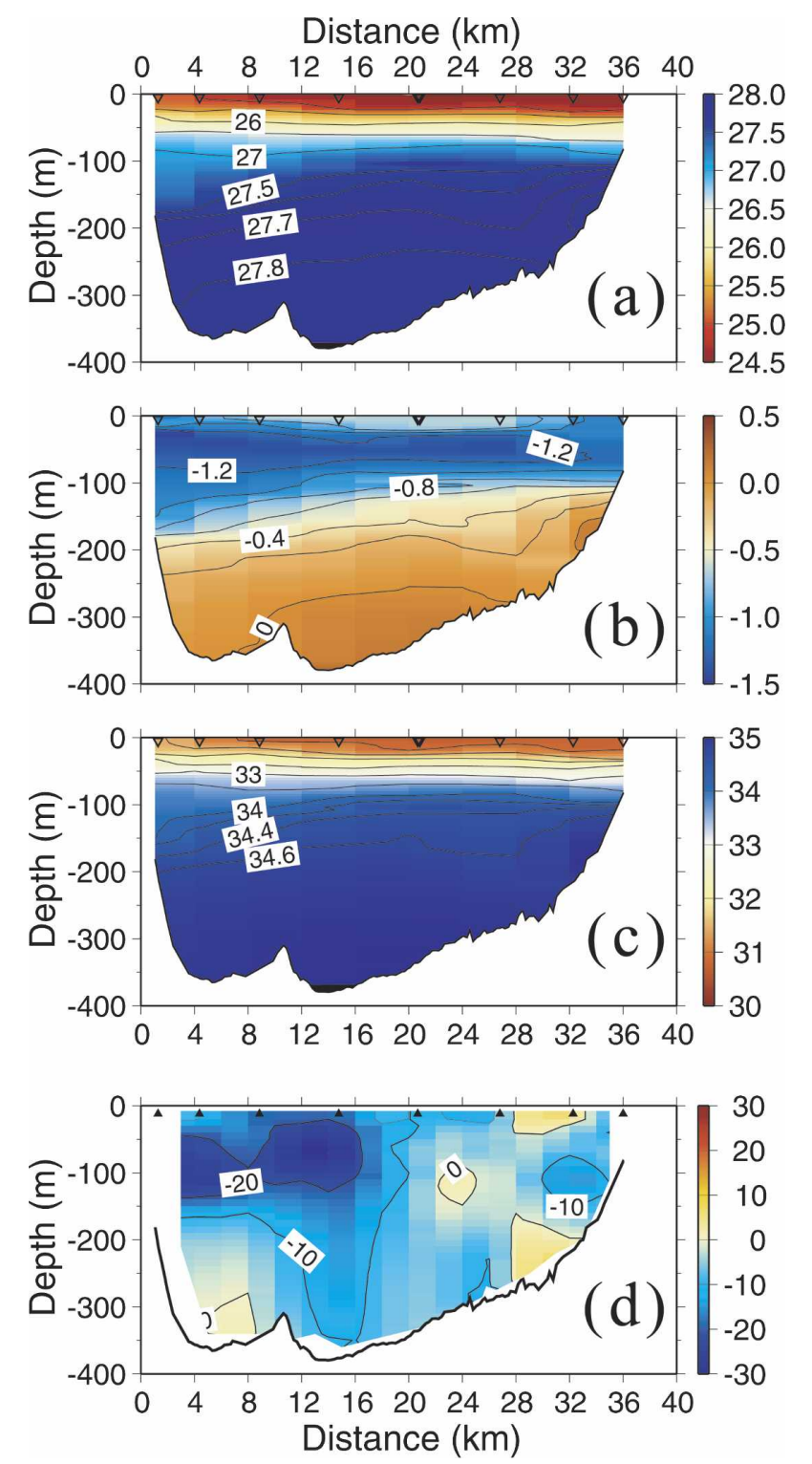

FIG. 6. Section across southern Kennedy Channel of (a) density anomaly, (b) temperature, (c) salinity, and (d) absolute geostrophic velocity using the thermal wind relation and ADCPderived barotropic reference velocity $V_{0}$ (triangles indicate CTD cast locations). The view is toward the northeast with Ellesmere Island on the left and Greenland on the right.

matches the spatial scale of the observed hydrographic feature and, as we discuss below, the observed velocity field. Here we use the constant of gravity $g \sim 9.81 \mathrm{~m} \mathrm{~s}^{-2}$, a density difference $\Delta \rho \sim \mathrm{kg} \mathrm{m}^{-3}$, a density $\rho \sim 1027 \mathrm{~kg}$ $\mathrm{m}^{-3}$, the Coriolis parameter $f \sim 1.44 \times 10^{-4} \mathrm{~s}^{-1}$, and a vertical scale of motion $D \sim 100 \mathrm{~m}$ (Gill 1982). The implied geostrophic dynamics, that is, a baroclinic pressure gradient balanced by the Coriolis force, permits estimation of the vertical shear in current from the measured density using the thermal wind balance (Gill 1982),

$$
\partial V_{g} / \partial z=g /\left(\rho_{0} f\right) \partial \rho / \partial x
$$

where $\partial V_{g} / \partial z$ is the geostrophic shear of the alongchannel velocity and $\partial \rho / \partial x$ is the cross-channel density gradient. The integral provides speed relative to a reference $V_{0}$,

$$
V_{g}(x, z)=V_{g}\left[x, z_{g}(x)\right]+\int_{z} g /\left(\rho_{0} f\right) \partial \rho / \partial x d z .
$$

In standard practice, the reference speed $V_{0}$ is assumed to be zero at some depth $z_{0}$ of no motion where pressure gradients are assumed to vanish. In this study, the reference speed was directly measured by the ADCP. With this additional information, we estimate a barotropic pressure gradient that in standard geostrophic (or dynamic height) calculation is ignored. We initially calculated $V_{g}(x, z)$ from hydrography assuming speed to be zero at the deepest level $z_{0}(x)$ for which we could estimate $\partial \rho / \partial x$. Figure 7a shows the resulting depth-average of $V_{g}(x, z)$ as well as the vertically averaged ADCP currents as a function of $\mathrm{x}$. The difference between these two is our reference velocity $V_{0}(x)$ shown in Fig. 7b, the barotropic component of the geostrophic flow. We estimated the barotropic pressure gradient assuming a geostrophic balance $f V_{0}=g \partial \eta / \partial x$ in the cross-channel direction and computed sea level variation (Fig. 7c) from

$$
\eta(x)=\int_{0}^{x}(f / g) V_{0}\left(x^{\prime}\right) d x^{\prime},
$$

where $\eta$ is the sea surface height relative to an arbitrary $\eta(x=0)=1.4 \mathrm{~cm}$. The sea level decreased by about 1.4 $\mathrm{cm}$ between Ellesmere Island and Greenland. Figure $6 \mathrm{~d}$ shows the absolute geostrophic velocity along Kennedy Channel. The net flow was southward, and much of the flux was confined to the western half of the channel above 200-m depth. A subsurface jet had maximum flow of $30 \mathrm{~cm} \mathrm{~s}^{-1}$ at $75-\mathrm{m}$ depth about $12 \mathrm{~km}$ from the Ellesmere coast. In the eastern half of the channel there was a zone of anticyclonic shear centered at 100-m depth and $28 \mathrm{~km}$ from Ellesmere Island. It is not possible with a single cross section to determine whether this feature was an eddy or a northward jet pushing into the generally southward flow at the entrance to Kennedy Channel. We note that at the time of this survey, pack ice was drifting northward along the Greenland coast from Kane Basin (see also Fig. 2).

Because of the strong baroclinic character of the flow in Kennedy Channel in August 2003, it was essential that the internal Rossby radius be resolved for reliable 

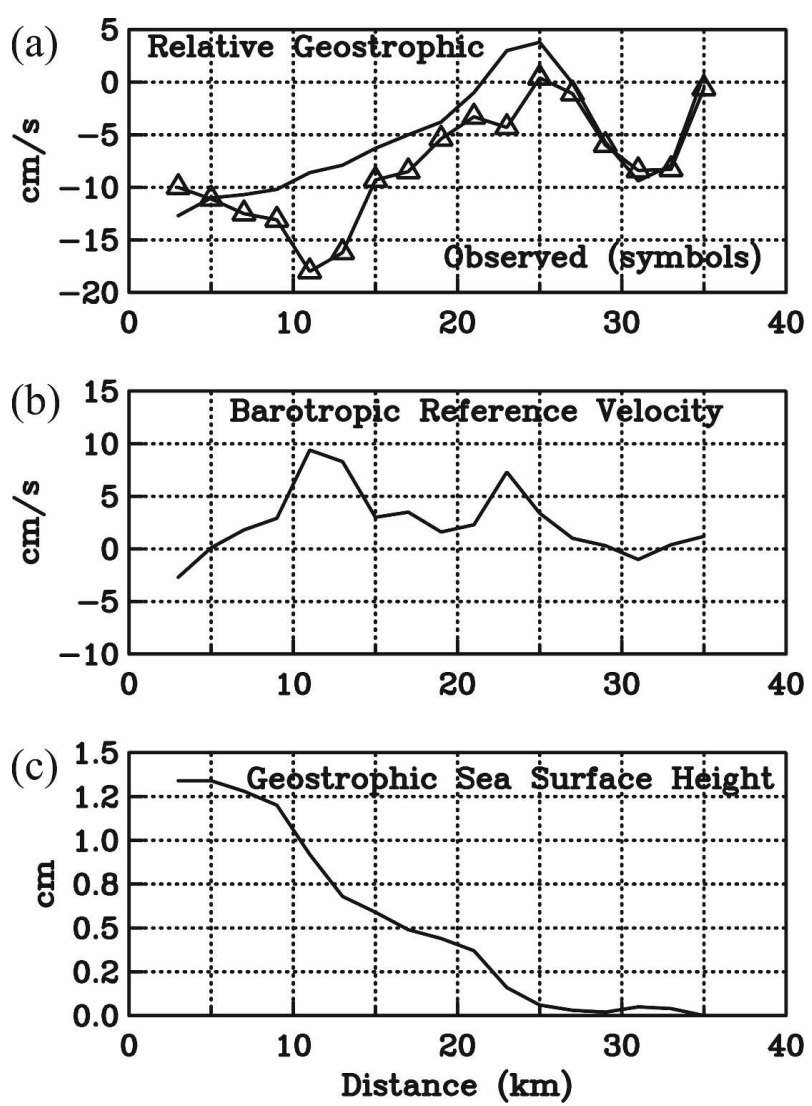

FIG. 7. Cross-channel profiles of (a) vertically averaged relative geostrophic current from the thermal wind calculation (solid line) and vertically averaged currents from the ADCP (solid line with symbols); (b) difference between geostrophic and measured currents, equivalent to the barotropic reference velocity $V_{0}$; (c) sea level estimated from $V_{0}$.

mapping of the flow field and estimation of fluxes without spatial aliasing. Integrating the geostrophic velocity across the section in Fig. 6d, we determine a total volume flux of about $0.8 \pm 0.1 \mathrm{~Sv}$; the error estimate is based on a $1 \mathrm{~cm} \mathrm{~s}^{-1}$ uncertainty associated with imperfect detiding and random measurement errors. About one-third of this flux $(0.27 \mathrm{~Sv})$ was associated with the reference velocity $V_{0}(x)$. We now proceed to examine the directly measured currents in detail, describing the resolution and subsequent removal of tidal currents.

\section{Tidal velocity estimation}

On the section just discussed, at the southern end of Kennedy Channel, oceanic flows were measured opportunistically in conjunction with mooring operations. Tidal currents are a dominant signal that must be accurately quantified and carefully removed from the record. We used two independent methods to estimate tidal currents. The first was a numerical model of barotropic tidal currents (Padman and Erofeeva 2004) that predicts depth-averaged tidal currents on a 5 -km horizontal grid; the second relied upon the method of least squares to minimize residual tidal variance in the data (Münchow et al. 2000; Münchow 2000) assuming vertical, but no horizontal gradients of tidal properties within the limited study area. Both methods proved sufficiently accurate for volume flux estimation. In contrast, only the least squares method generated estimates of tidal current that were sufficiently accurate for freshwater flux estimation. This is because the accuracy of estimates of freshwater flux is heavily reliant on the accuracy of current speed near the surface, where salinity is lowest.

The velocity determined by ADCP from a moving ship is a function of space and time, namely, $\mathbf{u}=\mathbf{u}[\mathbf{x}(t), t]$. Here, $\mathbf{u}=(U, V)$ and $\mathbf{x}=(x, y, z)$ are horizontal velocity and three-dimensional position vectors, respectively. Our coordinate system is shown in Figs. 3 and 4, rotated by $36^{\circ}$ clockwise from east; $x$ and $y$ represent cross- and along-channel location, and $U$ and $V$ the corresponding components of velocity. Distance is measured from the coast of Ellesmere Island toward Greenland. We have plotted a sample of the dataset in Fig. 8 as a function of time only, disregarding at present its spatial dependence. We compared vertically averaged velocity from the ADCP with numerical predictions of tidal current for the time of observation (Padman and Erofeeva 2004). The predictions have been derived from the harmonic coefficients of four semidiurnal and four diurnal tidal constituents that vary with position on a 5-km grid (Padman and Erofeeva 2004); the tidal flow is $\mathbf{u}_{t}=\mathbf{u}_{t}(x, y, t)$. Note that the observations contain contributions from signals over a wide range of frequencies including a mean flow and variations on the times scales ranging from seasons to time scales associated with storms, eddies, tides, inertial waves, and turbulence. Since the numerical model includes only deterministic tidal dynamics, a close agreement between data and simulations is not expected. Nevertheless, both the simulated flow and our observations contain a dominant along-channel tidal oscillation with an amplitude of 20-30 $\mathrm{cm} \mathrm{s}^{-1}$ (Figs. 9 and 10). Note the general offset of the observed along-channel current by about $10-20 \mathrm{~cm} \mathrm{~s}^{-1}$ from that predicted during the first $24 \mathrm{~h}$ of the time series. The observed flow was more negative, implying a southward subtidal or residual flow in Kennedy Channel at that time. This mean southward flow was consistent with hydrographic observations and the thermal wind equation as seen in Fig. 6d. The observed flow was counter to the direction of wind measured in the channel at the time; these blew 

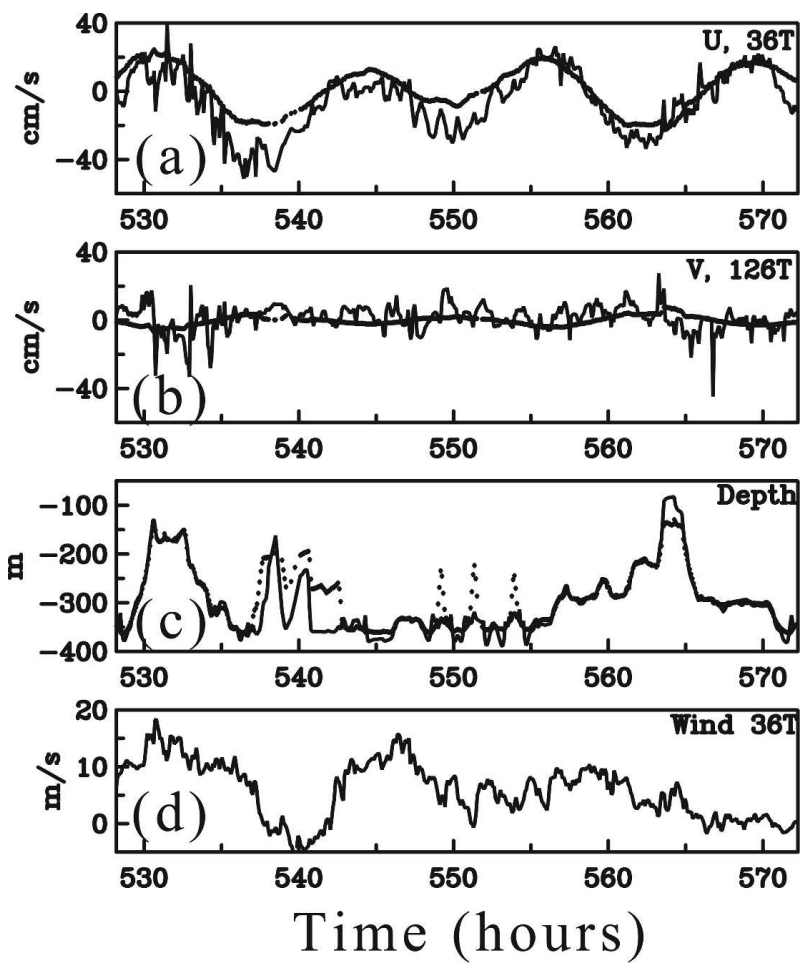

FIG. 8. Time series of (a) depth-averaged along-channel velocity, (b) depth-averaged cross-channel velocity, (c) bottom depth, and (d) along-channel wind. The symbols are properties predicted taken a barotropic tidal model for the time and location that the ADCP measurements were made.

from the southwest at speeds reaching $15 \mathrm{~m} \mathrm{~s}^{-1}$ (Fig. $8 d)$.

The concordance of observations with simulations in both phase and amplitude is encouraging, considering the many factors that influence both numerical and observational data. While the model assimilates sea level from satellite altimetry, these data originate from south of about $66^{\circ} \mathrm{N}$ (Padman and Erofeeva 2004). The remote location of Kennedy Channel precludes tuning of the model, since there are no nearby data to work with. Tidal flows from the model are quite sensitive to seafloor topography, since they are averaged over the water column. Bathymetry is poorly known on a $5-\mathrm{km}$ grid in many areas of the Arctic. Figure 8c reveals large discrepancies in our study area between the water depth observed and the International Bathymetric Chart of the Arctic Ocean (IBCAO; Jakobsson et al. 2000) that is used by the model. Discrepancies reach 100 $\mathrm{m}$ at $350 \mathrm{~m}$ depths, both adjacent to coasts and in the center of the channel.

Since tidal currents may vary with depth as well with horizontal position, it is important to assess how the modeling and observational approaches match in this regard. To investigate change with depth, we estimated
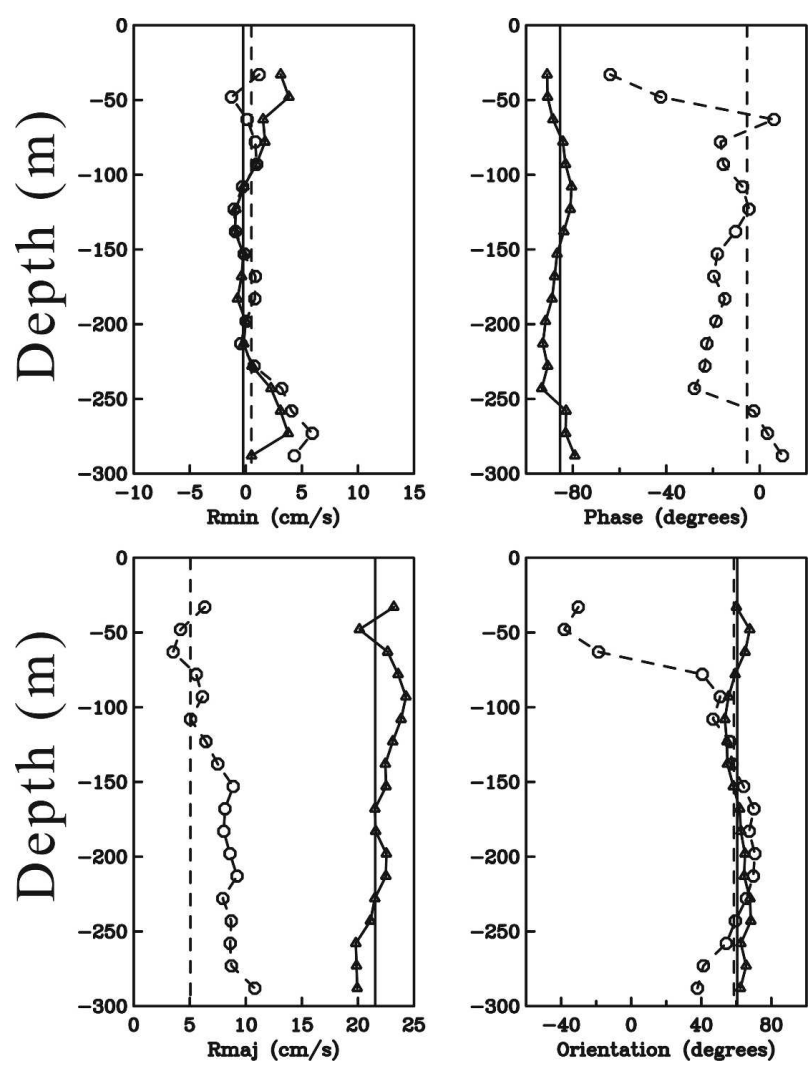

FIG. 9. Tidal ellipse parameters as a function of depth for semidiurnal $M_{2}$ (solid lines and triangles) and diurnal $K_{1}$ (dashed lines and circles) constituents. Symbols indicate vertical bins for which the (bottom left) semimajor $\left(R_{\text {maj }}\right)$ and (top left) semiminor $\left(R_{\min }\right)$ current amplitudes, (bottom right) semimajor axes orientation, and (top right) phases are shown. For the orientation and phase of the semimajor axis, positive angles are counterclockwise from the east, negative $R_{\min }$ indicate counterclockwise rotation. Solid and dashed vertical lines represent semidiurnal and diurnal ellipse parameters, respectively, estimated by minimizing least squares of velocity vectors predicted by the Padman and Erofeeva (2004) for the location and time ADCP velocity observations were made.

tidal currents at each level by fitting a semidiurnal and a diurnal constituent to our data using the method of least squares. For this discussion, we assumed that the tidal flow in our study area varied spatially as a function of depth only, that is, $\mathbf{u}_{t}=\mathbf{u}_{t}(z, t)$. Figure 9 shows the four parameters of the tidal ellipse for the principal semidiurnal $\left(M_{2}\right)$ and diurnal $\left(K_{1}\right)$ constituents. It also displays tidal ellipse parameters we find by subjecting to a least squares minimization or harmonic analysis a time series of the barotropic tide predicted by the Padman and Erofeeva (2004) model at the times and locations $(x, y, t)$ that velocity was sampled in our survey. Figure 9 reveals that the tidal currents at our section were largely barotropic. The semidiurnal current reached $25 \mathrm{~cm} \mathrm{~s}^{-1}$ and varied within $15 \%$ of the baro- 

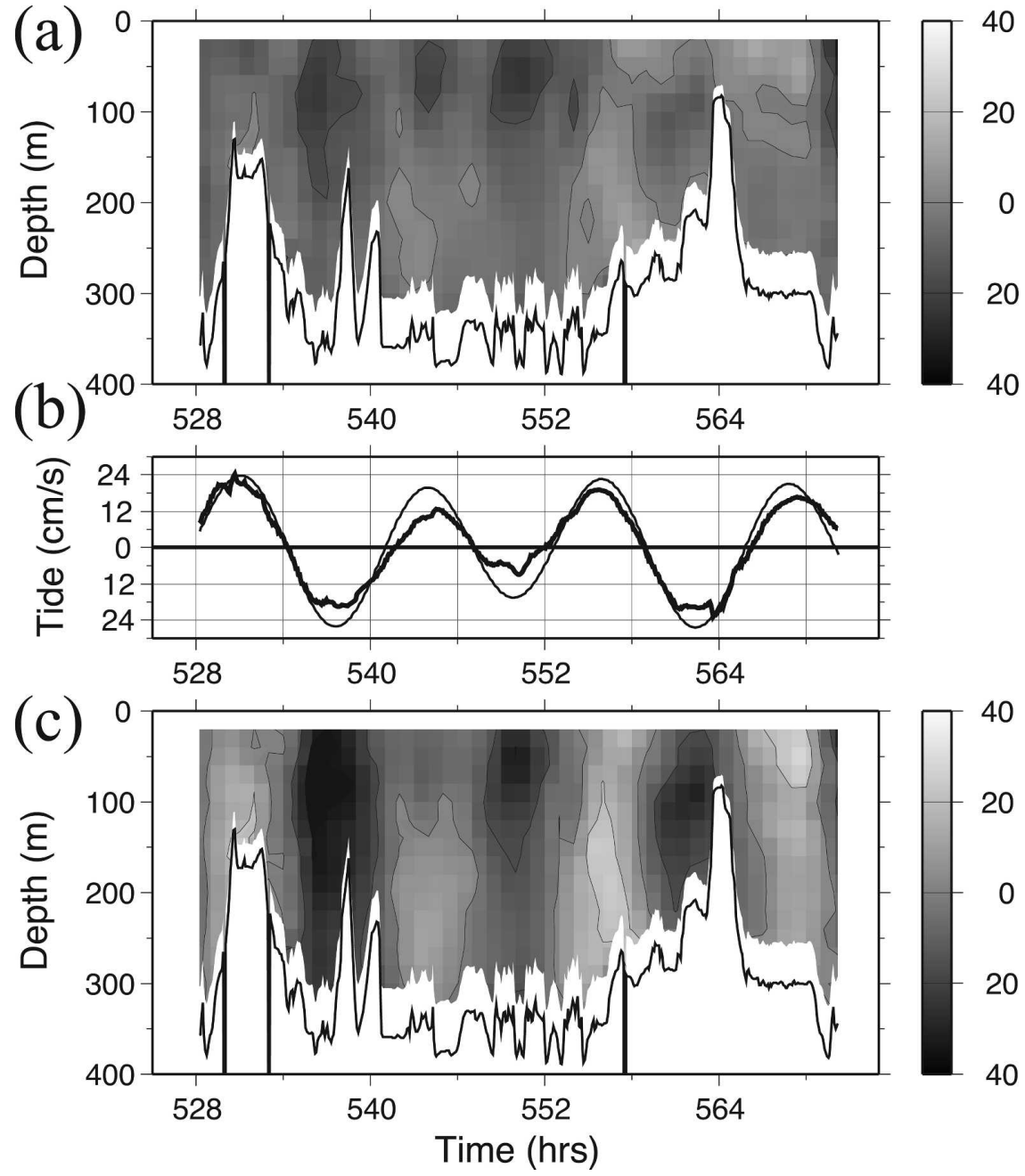

FIG. 10. Along-channel current in Kennedy Channel: (a) detided current vs time and depth, (b) tidal current predicted by numerical (thick line) and by least squares (thin line) models, and (c) raw data. Dark shades indicate flows to the southwest into Kane Basin (see Fig. 3 for locations and coordinate system).

tropic value of $21.5 \mathrm{~cm} \mathrm{~s}^{-1}$ for the semimajor axis $R_{\text {maj }}$; the semiminor axis $R_{\text {min }}$ was small. Tidal currents were also in phase over depth: variations did not exceed $10^{\circ}$, corresponding to a time lag of $20 \mathrm{~min}$. The reduction of $R_{\text {maj }}$ within $100 \mathrm{~m}$ of the bottom was likely caused by friction (Prandle 1982), which also induces small changes in ellipse orientation, phase and $R_{\min }$ with depth. We demonstrate below that the two detiding methods yield similar estimates for volume flux, but different results for freshwater flux.

Figure 10 is a graphical summary of our observations of along-channel current that emphasizes tidal variability. We observed tidal currents in Kennedy Channel that were mainly barotropic with strong oscillations at both semidiurnal and diurnal periods. Figure 10b compares the predictions of the numerical and least squares models, and Fig. 11 shows the detided current. Note the strong southward flows at hours 537 and 550 (Fig. 12), which might be construed as remnants of unresolved tidal variability, but, as Fig. 11b shows, they correspond to the strong and persistent southward flow off Ellesmere Island (see also Fig. 3 for the sampling in space and time). In Table 1 and Table 2 we present detided volume and freshwater flux estimates using both detiding methods as well as the results without any detiding.

\section{Detided velocity fields and fluxes}

The volume flux $q$ is defined as

$$
q=\int_{A} V(x, z) d A,
$$



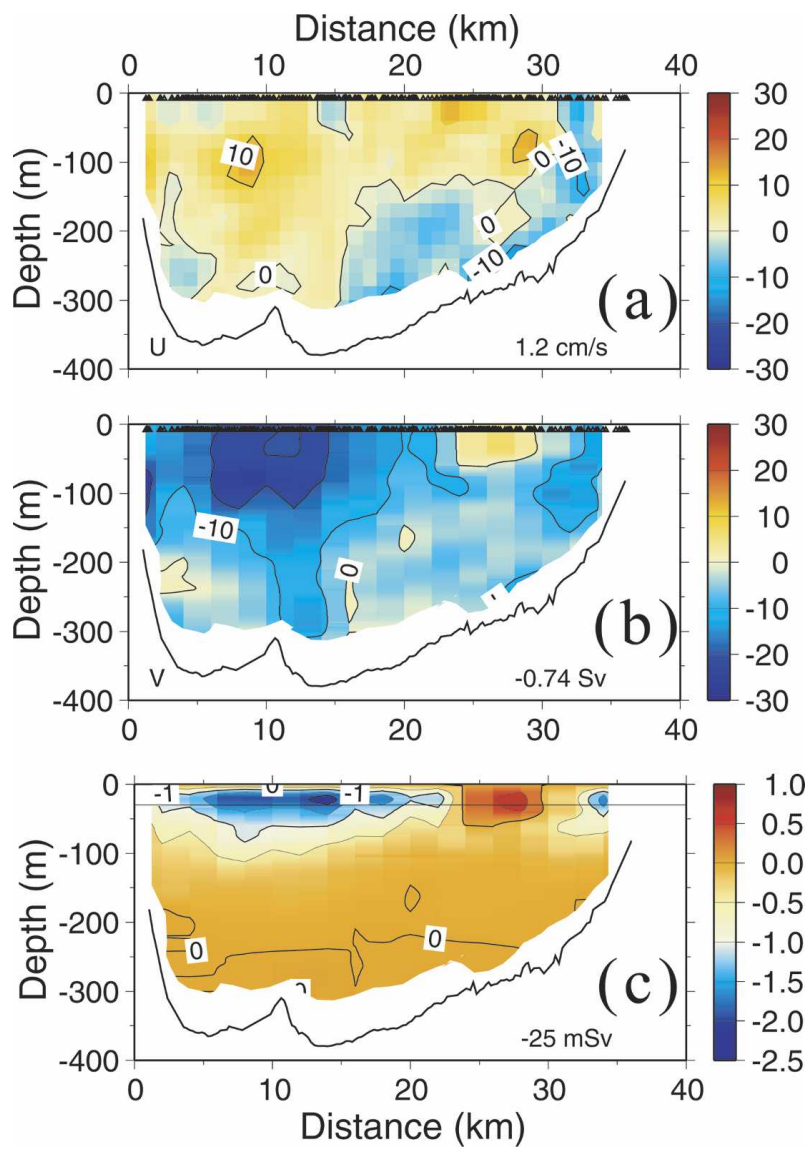

FIG. 11. Section of (a) detided cross-shore velocity $U$ with annotation for sectional average, (b) detided alongshore velocity $V$ with annotation for volume flux, and (c) freshwater flux per unit area $f_{A}$. The integral of this property over the section is $25 \mathrm{mSv}$. The flux above the horizontal line at $30 \mathrm{~m}$, which was calculated by extrapolation of measurements, contributes $22 \%$ of the total flux (Table 2).

where $V(x, z)$ is the velocity component normal to the sectional area $A$ in the $(x, z)$ plane. There are several ways to approximate the integral by averaging (detided) velocity data in time and space. We here present estimates from three different averaging schemes.

We start with the depth-averaged flow presented in Fig. 4, which estimates the barotropic velocity field. The detided velocity data are averaged into $2-\mathrm{km}$ bins $\Delta x$ along the section. With this approach the approximation to volume flux is

$$
q=\int_{x} V_{\mathrm{bar}}(x) H(x) d x \approx \sum_{i}\left[V\left(x_{i}\right) H\left(x_{i}\right) \Delta x_{i}\right]
$$

with $H\left(x_{i}\right)$ being the average water depth within the 2-km bin. This formulation effectively extrapolates the average flow to the surface and to the seabed across the

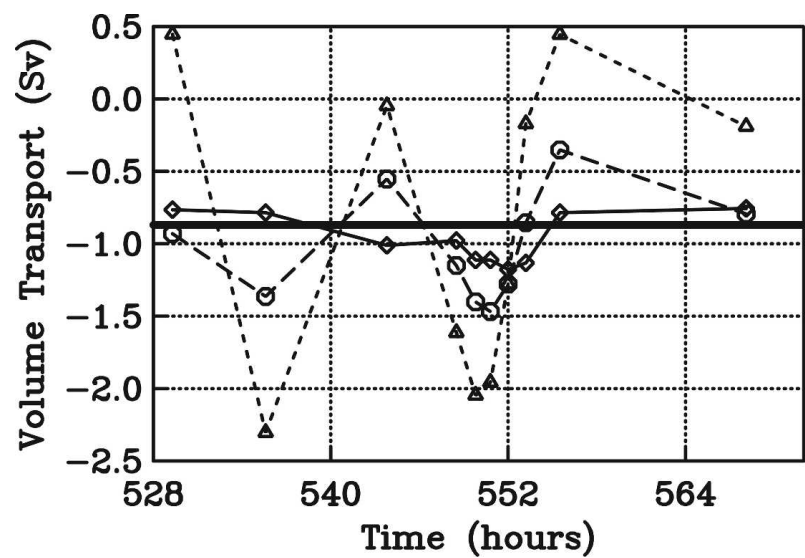

FIG. 12. Volume flux estimates through southern Kennedy Channel section with tides included (short dash with triangles), with Padman and Erofeeva (2004) detiding (long dash with circles), and with least squares detiding (thin line with diamonds). The thick line without symbols at $0.8 \mathrm{~Sv}$ indicates absolute geostrophic transport (Fig. 6d). The average of these individual estimates is $Q$, and standard error is $\varepsilon$ (see Table 1 ).

zones inaccessible to measurement by ADCP. The barotropic flux computed by this method for the section at the southern end of Kennedy Channel is $0.8 \pm 0.1 \mathrm{~Sv}$; the error estimate is based on a $1 \mathrm{~cm} \mathrm{~s}^{-1}$ uncertainty associated with random detiding and measurement errors. Much of the flux passed through the Canadian portion of the channel via $\sim 20 \mathrm{~cm} \mathrm{~s}^{-1}$ strong southward streams adjacent to the coast and near the channel center (Fig. 4). On the Greenland side, southward flow was weaker with a substantial cross-channel component.

In a second scheme we estimate the volume flux from all available (detided) velocity data after they are interpolated onto a single $\Delta x \times \Delta z$ grid with $\Delta x=2-\mathrm{km}$ across-channel and $\Delta z=10$-m vertical averaging interval, for example,

$$
Q_{\mathrm{tot}}=\int_{\mathrm{A}} V(x, z, t) d A \approx \sum_{i} \sum_{j}\left[V\left(x_{i}, z_{j}, t\right) \Delta x_{i} \Delta z_{j}\right] .
$$

Since the water depth $H$ is not explicitly included, this summation includes only the depth range that was actually profiled, thus excluding about $15 \%$ of the water column near the seabed and $18 \mathrm{~m}$ near the surface. Hence the flux estimate $Q_{\text {tot }}$ probably underestimates the unknown true flux. Table 1 summarizes the results for volume flux $Q_{\text {tot }}$, which ranged from -0.8 to -0.6 $\mathrm{Sv}$, with standard errors $\varepsilon$ ranging from \pm 0.3 to $\pm 1.1 \mathrm{~Sv}$ depending on how the tidal currents are or are not removed. These error estimates are derived from a third, and perhaps least reliable scheme to estimate transports that we elucidate next. Nevertheless, the as- 
TABLE 1. Volume flux estimates for Kennedy Channel using different detiding methods (rows) where $Q_{\text {tot }}$ averages all data onto a single gridded section, $Q_{\mathrm{bar}}$ is the average of $i=1,2, \ldots 10$ partial sections, and $\varepsilon$ is the standard error associated with 10 estimates $q_{i}$ whose average is $Q_{\mathrm{bar}} ; V_{\mathrm{bar}}$ is the sectionally average cross-channel velocity component that should be close to zero in a constrained channel flow.

\begin{tabular}{lcccc}
\hline \hline & $Q_{\text {tot }}(\mathrm{Sv})$ & $Q_{\text {bar }}(\mathrm{Sv})$ & $\varepsilon(\mathrm{Sv})$ & $V_{\text {bar }}\left(\mathrm{cm} \mathrm{s}^{-1}\right)$ \\
\hline No detiding & -0.6 & -0.8 & \pm 1.1 & 1.7 \\
Padman and Erofeeva (2004) detiding & -0.8 & -1.0 & \pm 0.5 & 2.1 \\
Least squares detiding & -0.7 & -0.7 & \pm 0.3 & 1.2 \\
\hline
\end{tabular}

sociated error statistics serve as upper bounds where otherwise no error estimate would be available.

Figure 3 depicts the sampling in time and space of 10 partial sections across southern Kennedy Channel that all traverse the deep central portion of the channel. Each section has a different area ranging from $3660 \times$ $10^{3}$ (crossings 5 and 6) to $8720 \times 10^{3} \mathrm{~m}^{2}$ (crossing 2). We scaled transport estimates of shorter sections upward to a standard area of $8720 \times 10^{3} \mathrm{~m}^{2}$ in order to compensate for differences of sectional area profiled by the ADCP. For example, if crossing 5 gives a flux of 0.5 Sv over $3660 \times 10^{3} \mathrm{~m}^{2}$ sectional area, this flux scales to $0.5 \times 8720 / 3660=1.2 \mathrm{~Sv}$. We thus assume that the profiled area of $3660 \times 10^{3} \mathrm{~m}^{2}$ was representative of an area equal to the standard area of $8720 \times 10^{3} \mathrm{~m}^{2}$. This assumption almost certainly inflates the southward transport as flows off Greenland are both weaker and less well resolved than those over the central channel and off Ellesmere Island. Our purpose here, however, is to conservatively estimate uncertainty from the temporal variability using the 10 noisy flux estimates that are shown in Fig. 12 as a time series $q_{j}=q_{j}\left(t_{j}\right)$. From this time series we derive a standard error $\varepsilon$ as the uncertainty in volume flux, for example,

$$
\varepsilon=\left[\sum_{i}\left(q_{i}-Q_{\mathrm{bar}}\right)^{2} /(N-1)\right]^{1 / 2}
$$

where $Q_{\mathrm{bar}}$ is the algebraic mean of fluxes $q_{i}$ calculated for $i=1,2, \ldots, N=10$ individual sections. Note that $Q_{\text {bar }}$ differs from the total volume flux $Q_{\text {tot }}$. As stated above, we calculate $Q_{\text {tot }}$ using data from all available sections irrespectively of time to form a single grid of the entire channel. In contrast, $Q_{\mathrm{bar}}$ represents an algebraic average of scaled volume fluxes from individual and partial cross sections whose flux values have been scaled to a common (standard) area. We interpret the standard error $\varepsilon$ of $Q_{\mathrm{bar}}$ as a conservative estimate of uncertainty for the total volume flux $Q_{\text {tot }}$. Note that both $Q_{\text {bar }}$ and $Q_{\text {tot }}$ are about $10 \%$ smaller than volume flux derived using Eq. (6) as we did not include the lowest $15 \%$ of the water column where the Doppler sonar is ineffective.

Figure 12 indicates that the oscillatory tidal volume flux has an amplitude of about $1.5 \mathrm{~Sv}$. The most reliable estimate of subtidal volume flux is $0.7 \pm 0.3 \mathrm{~Sv}$, derived with tides removed using the method of least squares that ignores horizontal, but resolves vertical variability of tidal constituents. Detiding using the method of Padman and Erofeeva (2004) that ignores vertical, but resolves horizontal variability of tidal constituents generates the value $0.8 \pm 0.5 \mathrm{~Sv}$. It is clear from Fig. 12 that detiding with the Padman and Erofeeva (2004) predictions was not optimal; there is a residual tidal oscillation with $0.4-\mathrm{Sv}$ amplitude. Least squares detiding resulted in smaller residual tidal signal $(0.2 \mathrm{~Sv})$, smaller standard error $(0.3 \mathrm{~Sv})$, smaller average cross-channel flow $(0.4$ $\left.\mathrm{cm} \mathrm{s}^{-1}\right)$, and smaller volume flux $(0.7 \mathrm{~Sv})$.

The spatial distribution of current within the section reflects dynamical issues that must be clarified and understood before accurate monitoring and modeling of fluxes through Nares Strait become practical. Figure 11 shows the along- and cross-channel components of velocity. There was southward flow near Ellesmere Island and northward flow near Greenland. The surface wind was from the southwest at the time, thus opposing the oceanic flow over much of the section (Fig. 8). Downchannel current peaked at $25 \mathrm{~cm} \mathrm{~s}^{-1}$ about $80 \mathrm{~m}$ below the surface. Associated with this jet was a $10 \mathrm{~cm} \mathrm{~s}^{-1}$ cross-channel (southeastward) component about $8 \mathrm{~km}$ from Ellesmere Island. A second high southward ve-

TABLE 2. As in Table 1, but for freshwater flux estimates in Kennedy Channel. Values in parentheses exclude the 30-m surface layer, while values without brackets represent fluxes that use extrapolated surface velocities.

\begin{tabular}{llccc}
\hline \hline & $F_{\mathrm{tot}}(\mathrm{mSv})$ & $F(\mathrm{mSv})$ & $\varepsilon(\mathrm{mSv})$ & $F_{\mathrm{tot}}\left(\mathrm{km}^{3} \mathrm{yr}-1\right)$ \\
\hline No detiding & $-27(-21)$ & $-36(-27)$ & $\pm 33(25)$ & $-860 \pm 1100$ \\
Padman and Erofeeva (2004) detiding & $-30(-23)$ & $-40(-30)$ & $\pm 18(13)$ & $-950 \pm 580$ \\
Least squares detiding & $-25(-23)$ & $-28(-22)$ & $\pm 12(9)$ & $-920 \pm 380$ \\
\hline
\end{tabular}


locity core was evident at about kilometer 3 off Ellesmere Island at $100 \mathrm{~m}$ depth. The northward flow on the Greenland side near kilometer 25 was confined to the uppermost $50 \mathrm{~m}$, and coincident with a convergence of the cross-channel flow. The northeasterly flow at this location carried ice and melt-freshened seawater from Kane Basin into the study area. The distribution of pack ice revealed by the MODIS sensor on 12 August 2003 (Fig. 2c) is similar to that encountered during our surveys one week earlier. Although the impact of this circulation feature on volume flux was minimal, its effect on freshwater flux was more pronounced. These we discuss next.

The freshwater flux is the integral over area $A$ of the correlation between the velocity component normal to the section and salinity anomaly relative to a reference value $S_{0}$, here chosen to be 34.8 so as to be comparable to previous estimates of freshwater fluxes at Arctic gateways (Melling 2000):

$$
F=\int_{A} f_{A}(x, z) d A
$$

where

$$
f_{A}(x, z)=V(x, z)\left\{1-\left[S(x, z)+s_{t}\right] / S_{0}\right\} .
$$

The salinity $S(x, z)+s_{t}$ and along-channel speed $V(x$, $z)$ are shown in Fig. 6c and Fig. 11, respectively, where the velocity, but not the salinity field has the tidal variability removed. The variable $s_{t}$ indicates the unknown tidal component of the salinity field. Recall from our previous discussion that surface salinity measurements (not shown) indicate that spatial gradients at the scale of tidal excursion of 13 and $1 \mathrm{~km}$ in along- and acrosschannel directions. These introduce salinity errors less than 0.2 and $0.01 \mathrm{psu}$, respectively; hence we can ignore across-channel salinity variations as the across-channel tidal currents and salinity gradients are small relative to the along-channel tidal current and salinity gradients. Estimating an upper bound of this potential tidal salinity bias, we assume that a maximum tidal oscillation of $s_{t} \sim 0.2 \mathrm{psu}$ is distributed uniformly over the entire section. We furthermore ignore any phase variations within the section and thus find an upper bound for the tidal salinity bias as $Q \times s_{t} / S_{0} \sim 0.8 \mathrm{~Sv} \times 0.2 / 34.8 \sim 5$ $\mathrm{mSv}\left(1 \mathrm{mSv}=10^{3} \mathrm{~m}^{3} \mathrm{~s}^{-1}\right)$ or about $16 \%$ of the freshwater flux value of $25 \mathrm{mSv}$ that we will find below.

As a second caveat we note that the freshwater flux is very sensitive to salinity and velocity within $30 \mathrm{~m}$ of the surface since the salinity is low within this layer. Hence we will present results using two different assumptions regarding the top $30 \mathrm{~m}$ of the column in

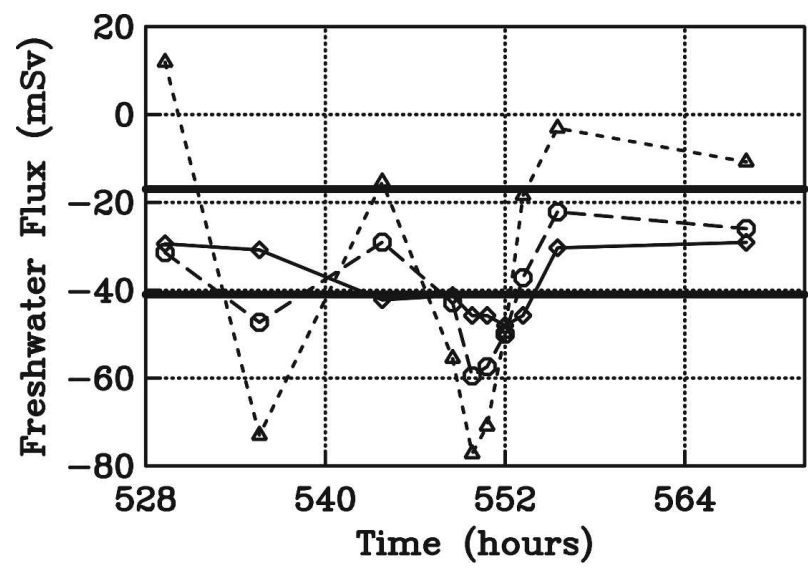

FIG. 13. As in Fig. 12, but for freshwater flux. Note the large tidal oscillation in the raw freshwater flux (short dash with triangles) that is much reduced after detiding. Note also that the Padman and Erofeeva (2004) detiding (long dash with circles) does not predict surface currents adequately to remove dominant tidal oscillations in freshwater flux. The thick lines indicate the upper and lower bounds of the mean flux $(25 \pm 12 \mathrm{mSv})$.

order to provide bounds for our estimates of freshwater flux. For a lower bound, we excluded the top $30 \mathrm{~m}$ from our freshwater flux calculation entirely; the resulting values are listed in Table 2 within closed brackets. More realistically, we assumed no change in current speed above the shallowest depth of measurement, and used the average value measured between 18- and 48-m depth as the current speed in the surface layer. Results are listed in Table 2; Figs. 11c and 13 display spatial and temporal variations in freshwater flux, respectively.

Estimates of the total freshwater flux in early August 2003 are $-25 \pm 12 \mathrm{mSv}$ using the least squares detiding method and $-30 \pm 18 \mathrm{mSv}$ using that of Padman and Erofeeva (2004). The uncertainties here reflect tidal and subtidal velocity variability expressed as the standard error from the mean of 10 incompletely profiled sections [see discussion of Eq. (8)]. Note in Fig. 13 the large residual tidal fluctuation in the freshwater flux detided by the numerical model. At hour 550 the poorly detided freshwater flux $(-60 \mathrm{mSv})$ almost matched the tidally biased freshwater flux from the raw data. The barotropic tidal model does not properly represent the near-surface currents for freshwater flux calculations. Before removal of tidal currents, the freshwater flux was zero within estimated error (Table 2; Fig. 13), as also true of volume flux. Hence a properly detided oceanic flow field is an essential component of accurate flux estimates within the three or four tidally dominated choke points for flow through the Canadian Archipelago. In addition, most of the freshwater flux is carried within the upper $100 \mathrm{~m}$ of the water column, as noted by Melling (2000). Even under the conservative 
extrapolation used here (no shear in the surface Ekman layer), almost one-quarter of the freshwater flux (22\%) occurred in the top $30 \mathrm{~m}$ (Fig. 11c; Table 2). The freshwater flux relative to 34.8 salinity dwindled below $100-\mathrm{m}$ depth as salinity approached the reference and flow speed decreased. Figure $11 \mathrm{c}$ reveals a small-scale baroclinic feature at $x=28 \mathrm{~km}$ above $50-\mathrm{m}$ depth that transported seawater of low salinity to the northeast, thereby reducing the net Arctic outflow. Since ice was also drifting northward up the channel at this time as a result of winds from south, there may also have been a northeastward freshwater flux within the top $30 \mathrm{~m}$ over some of or perhaps even the entire channel width. The requirement to resolve narrow coastal boundary currents and shallow surface layers for accurate estimation of freshwater flux in straits presents a substantial observational challenge.

\section{Summary and conclusions}

We have estimated the mean volume and freshwater fluxes through Nares Strait at subtidal frequencies in early August 2003 to be $-0.8 \pm 0.3 \mathrm{~Sv}$ and $-25 \pm 12$ $\mathrm{mSv}$, respectively. The estimates are based on observations that resolved the fundamental spatial scale of flow, the internal Rossby radius (9 $\mathrm{km}$ here). However, they represent a snapshot in time and should not be construed as indicative of long-term average flows. The volume flux out of the Arctic Ocean through Nares Strait during our two days of observation is comparable to that entering through the Bering Strait; the freshwater flux is about one-half that of Bering Strait (Woodgate and Aagaard 2005). In contrast, the net volume flux leaving the Arctic via Fram Strait is much larger, Schauer et al. (2004) give annual mean transports in the range from $2 \pm 2 \mathrm{~Sv}$ to $4 \pm 2 \mathrm{~Sv}$, however, Fram Strait at $80^{\circ} \mathrm{N}$ is $500 \mathrm{~km}$ wide while the width of Nares Strait is only $40 \mathrm{~km}$.

Yang (2005) has commented that the flux of potential vorticity has a profound influence on the circulation of a semienclosed basin. More specifically, he has determined that the circulation of the Arctic Ocean is controlled by the distribution of potential vorticity $\Pi_{i}=$ $f Q_{i} / H_{i}$ at the inflow and outflow locations $i$; here $Q_{i}$ is a volume flux, $H_{i}$ is the water depth, and $f$ is the Coriolis parameter. The imbalance of vorticity between inflow and outflow determines the sense of circulation in the Arctic Ocean via dissipative processes along the boundary. Analyzing results from a numerical model, Yang (2005) finds that the flux of vorticity through Bering Strait dominates those passing through from the northern Barents Sea and Fram Strait:

$$
\prod_{\text {tot }}=\prod_{\text {Bering }}+\prod_{\text {Barents }}+\prod_{\text {Fram }}=+1.1+0.8-0.1 \mathrm{~m}^{2} \mathrm{~s}^{-2} .
$$

The net influx of potential vorticity to the Arctic is about $1.8 \mathrm{~m}^{2} \mathrm{~s}^{-2}$. Yang's model does not include the Canadian Archipelago. Using $H(300 \mathrm{~m}), Q_{\text {Nares }}(-0.8$ $\mathrm{Sv})$ and $f\left(1.44 \times 10^{-4} \mathrm{~s}^{-1}\right)$ for Nares Strait, we estimate $\Pi_{\text {Nares }}$ as $-0.4 \mathrm{~m}^{2} \mathrm{~s}^{-2}$, a significant term relative to values in Eq. (10), and a contribution to negative (anticyclonic) vorticity tendency in the Arctic Ocean.

Nares Strait fluxes are embedded in a velocity field that is dominated by barotropic tidal currents. The diurnal and semidiurnal oscillations in volume and freshwater fluxes exceed the daily mean fluxes by more than $100 \%$. However, much of the tidal variance is deterministic and thus predictable. We have used two independent methods to remove tidal effects. The highresolution numerical model of depth-averaged Arctic tides (Padman and Erofeeva 2004) was effective in minimizing the tidal signals in volume flux, but did less well with freshwater flux. An alternative empirical model of tidal currents allowed for vertical, but not horizontal variation over a limited domain; tidal constituents were determined by least squares fitting. The model also provided estimates of error in derived values. The least squares model generated tidal constituents that compared well to predictions of the numerical model except near the sea surface. These have value both for determination of subtidal fluxes of volume and freshwater, as well as in their own right in defining the amplitudes and phases of the semidiurnal and diurnal currents.

Our synoptic measurements revealed a structured and coherent flow field. There was a net southward flow over the western part of the section, strongest near $100 \mathrm{~m}$ depth and much reduced both above and below this depth. At the time of observation, wind from the southwest exerted an opposing stress at the sea surface. Isopycnals above about 100-m depth near the Ellesmere coast upwelled toward the surface, while deeper isopycnals sloped downward. Isopycnal slopes were greatest within an internal deformation radius of the western shore. The measured current of $30 \mathrm{~cm} \mathrm{~s}^{-1}$ was consistent with a geostrophic balance with the observed pressure field. Assuming geostrophy and using the measured distribution of density and depth-averaged current, we estimated the absolute geostrophic velocity field including a contribution from a sloping sea surface. We calculated a drop in sea level by about $1 \mathrm{~cm}$ over $15 \mathrm{~km}$ across the surveyed section. The barotropic contribution to the total flux of $0.8 \mathrm{~Sv}$ was about $32 \%$. 
If the flow in Nares Strait is geostrophic, as suggested by our observations (Fig. 6c and Fig. 11), then the Rossby number, Ro $\sim(V / L) / f$ must be much less than 1. We calculate a value of 0.13 using $(\Delta V / \Delta x) / f ; \Delta V \sim$ $0.2 \mathrm{~m} \mathrm{~s}^{-1}$ is the maximum velocity difference over a distance of $\Delta x \sim 10 \mathrm{~km}$. As the Rossby number scales the nonlinear inertial forces in the momentum balance relative to the Coriolis force, we conclude that nonlinear inertial terms are also small.

The established flow of seawater from Pacific to Atlantic Oceans through the Arctic has been attributed to higher sea level in the Pacific (Wijffels et al. 1992), associated with the lower salinity of Pacific waters. Sea level in the Atlantic may be more than $0.5 \mathrm{~m}$ lower than in the Pacific and 0.1-0.3 m lower than in the Arctic (Muench 1971). More accurate estimates of steric forcing have yet to be determined, but it is probably safe to conclude that much of the drop in sea level between Arctic and Atlantic Ocean occurs along the 530-km length of Nares Strait, thereby providing the impetus for the fluxes that we have measured.

We emphasize that our flux estimates are representative only of the few days of observation. Although the values are plausible and in line with other longer-term estimates for the Canadian Arctic Archipelago (Prinsenberg and Hamilton 2005) we do not at present know how much they are perturbed from long-term averages by forcing on synoptic, seasonal, and interannual time scales. Nor do we fully understand the dynamics of these fluxes. The close correspondence of our volume flux estimate $(0.8 \pm 0.3 \mathrm{~Sv})$ to the $0.6 \pm 0.1 \mathrm{~Sv}$ of Sadler (1976) is likely fortuitous as the latter were derived from 2-month averages, but much less well resolved in space. At present, there is an array of seven bottommounted ADCPs and eight conductivity-temperature (CT) strings moored in Nares Strait. In August 2006, we successfully recovered four ADCPs and six CTs from the section across Kennedy Channel. All instruments have full 3-yr data records. Data from these instruments will aid estimation of long-term average fluxes of volume, freshwater, and vorticity at longer time scales and give enhanced insights into temporal variability and its forcing.

Acknowledgments. We are grateful to the officers and crew of the USCGC Healy, commanded by Captain Oliver, who endorsed our scientific objectives in a professional and enthusiastic fashion. We benefited greatly from the efforts of Jules Hummon of the University of Hawaii, who recommended installation of the 75-kHz ADCP after initial sea trials in 2001, and of David Forcucci (USCG), who facilitated the purchase and installation of this and many related sensor sys- tems. Charlie Flagg helped the senior author on the steep learning curve of Healy ADCP data processing during an intense 2-day visit and shared his experiences running the Healy ADCP in 2002. Helen Johnson, Bob McCarthy, and students Elinor Keith, Lauren Brown, Melissa Zweng, and Helga Schaffrin competently monitored the system at all hours. The data from a single Lincoln Sea CTD cast in Fig. 5 were provided by Mike Steele of the University of Washington. Critical comments by Richard Garvine, Rebecca Woodgate, and three anonymous reviewers improved an early draft of this manuscript. We gratefully acknowledge that the material of this study is based upon work supported by the National Science Foundation under Grants 0230236 (AM and HM), 0230354 (KKF), and 0230427 (MS). Any opinions, findings, and conclusions or recommendations expressed in this material are those of the authors and do not necessarily reflect the views of the National Science Foundation.

\section{REFERENCES}

Aagaard, K., and E. C. Carmack, 1989: The role of sea ice and other freshwater in the Arctic circulation. J. Geophys. Res., 94, 14 485-14 498.

Belkin, I. M., S. Levitus, J. Antonov, and S.-A. Malmberg, 1998: "Great Salinity Anomalies" in the North Atlantic. Progress in Oceanography, Vol. 41, Elsevier, 1-68.

Bourke, R. H., V. G. Addison, and R. G. Paquette, 1989: Oceanography of Nares Strait and Northern Baffin Bay in 1986 with emphasis on deep and bottom water formation. J. Geophys. Res., 94, 8289-8302.

Cuny, J., P. B. Rhines, and R. Kwok, 2005: Davis Strait volume, freshwater and heat fluxes. Deep-Sea Res. I, 52, 519-542.

Curry, R., B. Dickson, and I. Yashayaev, 2003: A change in the freshwater balance of the Atlantic Ocean over the past 4 decades. Nature, 426, 826-829.

Dickson, R. R., J. Meincke, S. A. Malmberg, and A. J. Lee, 1988: The "Great Salinity Anomaly" in the northern North Atlantic 1968-1982. Progress in Oceanography, Vol. 20, Elsevier, 103-151.

_ I. Yashayaev, J. Meincke, W. Turrell, S. Dye, and J. Holfort, 2002: Rapid freshening of the deep North Atlantic Ocean over the past four decades. Nature, 416, 832-837.

—, R. Curry, and I. Yashayaev, 2003: Recent changes in the North Atlantic. Philos. Trans. Roy. Soc. London, A361, 1917-1934.

Falkner, K. K., M. Steele, R. A. Woodgate, J. H. Swift, K. Aagaard, and J. Morison, 2005: Dissolved oxygen extrema in the Arctic Ocean halocline from the North Pole to the Lincoln Sea. Deep-Sea Res., 52, 1138-1154.

Gill, A. E., 1982: Atmosphere-Ocean Dynamics. Academic Press, $662 \mathrm{pp}$

Hummon, J. M., and E. Firing, 2003: A direct comparison of two RDI shipboard ADCPs: A 75-kHz ocean surveyor and a 150kHz narrow band. J. Atmos. Oceanic Technol., 20, 872-888.

Ingvaldsen, R. B., L. Asplin, and H. Loeng, 2004: Velocity field of the western entrance to the Barents Sea. J. Geophys. Res., 109, C03021, doi:10.1029/2003JC001811. 
Jakobsson, M., N. Cherkis, J. Woodward, B. Coakley, and R. Macnab, 2000: A new grid of Arctic bathymetry: A significant resource for scientists and mapmakers. Eos, Trans. Amer. Geophys. Union, 81, 89, 93, 96.

Joyce, T. M., 1989: On in situ calibration of shipboard ADCPs. J. Atmos. Oceanic Technol., 6, 169-172.

Khatiwala, S. P., R. G. Fairbanks, and R. W. Houghton, 1999: Freshwater sources to the coastal ocean off northeastern North America: Evidence from $\mathrm{H}_{2}{ }^{18} \mathrm{O} / \mathrm{H}_{2}{ }^{16} \mathrm{O}$. J. Geophys. Res., 104, 18 241-18 255.

Kwok, R., 2006: Nares Strait ice flux. Geophys. Res. Lett., 32, L24502, doi:10.1029/2005GL024768.

LeBlond, P. H., T. R. Osborne, D. O. Hodgins, R. Goodman, and M. Metge, 1981: Surface circulation in the western Labrador Sea. Deep-Sea Res., 28A, 683-693.

Lozier, M. S., and M. S. C. Reed, 2005: The influence of topography on the stability of shelfbreak fronts. J. Phys. Oceanogr., 35, 1023-1036.

Melling, H., 2000: Exchange of freshwater through the shallow straits of the North American Arctic. The Freshwater Budget of the Arctic Ocean, E. L. Lewis et al., Eds., Kluwer Academic, 479-502.

—, R. A. Lake, D. R. Topham, and D. B. Fissel, 1984: Oceanic thermal structure in the western Canadian Arctic. Cont. Shelf Res., 3, 233-258.

Muench, R. D., 1971: The physical oceanography of the northern Baffin Bay region. North Water Project Scientific Rep. 1, Arctic Institute of North America, University of Calgary, Calgary, Canada, $150 \mathrm{pp}$.

Münchow, A., 2000: Detiding three-dimensional velocity survey data in coastal waters. J. Atmos. Oceanic Technol., 17, 736748

— E. C. Carmack, and D. A. Huntley, 2000: Synoptic density and velocity observations of slope waters in the Chukchi and East Siberian Seas. J. Geophys. Res., 105, 14 103-14 119.

Munk, W., 2003: Ocean freshening, sea level rising. Science, 300, 2041-2043.

Nutt, D. C., 1966: The drift of Ice Island WH5. Arctic, 19, 244-262.

Padman, L., and S. Erofeeva, 2004: A barotropic inverse tidal model for the Arctic Ocean. Geophys. Res. Lett., 31, L02303, doi:10.1029/2003GL019003.

Pickart, R. S., D. J. Torres, and R. A. Clarke, 2002: Hydrography of the Labrador Sea during active convections. J. Phys. Oceanogr., 32, 428-457.

—, M. A. Spall, M. H. Ribergaard, G. W. K. Moore, and R. F. Milliff, 2003: Deep convection in the Irminger Sea forced by the Greenland tip jet. Nature, 424, 152-156.

, D. J. Torres, and P. S. Fratantoni, 2005: The East Greenland spill jet. J. Phys. Oceanogr., 35, 1037-1053.
Prandle, D., 1982: The vertical structure of tidal currents. Geophys. Astrophys. Fluid Dyn., 22, 29-49.

Prinsenberg, S. J., and J. Hamilton, 2005: Monitoring the volume, freshwater and heat fluxes passing through Lancaster Sound in the Canadian Arctic Archipelago. Atmos.-Ocean, 43 (1), $1-22$.

Ronski, S., and G. Budéus, 2005: Time series of winter convection in the Greenland Sea. J. Geophys. Res., 110, C04015, doi:10.1029/2004JC002318.

Rossby, C.-G., 1937: On the mutual adjustment of pressure and velocity distributions in certain simple current systems. $J$. Mar. Res., 1, 15-28.

Sadler, H. E., 1976: Water, heat and salt transports through Nares Strait, Ellesmere Island. J. Fish. Res. Board Can., 33, 22862295.

Samelson, R. M., T. Agnew, H. Melling, and A. Münchow, 2006 Evidence for atmospheric control of ice-motion through Nares Strait. Geophys. Res. Lett., 33, L02506, doi:10.1029/ 2005 GL025016.

Schauer, U., E. Fahrbach, S. Osterhus, and G. Rohardt, 2004: Arctic warming through the Fram Strait: Oceanic heat transport from 3 years of measurements. J. Geophys. Res., 109, C06026, doi:10.1029/2003JC001823.

Serreze, M. C., and Coauthors, 2000: Observational evidence of recent change in the northern high-latitude environment. Climate Change, 46, 159-207.

Smith, E. H., F. M. Soule, and O. Mosby, 1937: The Marion and General Greene Expeditions to Davis Strait and Labrador Sea. U.S. Coast Guard Bulletin 19, U.S. Government Printing Office, $199 \mathrm{pp}$.

Wijffels, S. E., R. W. Schmitt, H. L. Bryden, and A. Stigebrandt, 1992: Transport of freshwater by the oceans. J. Phys. Oceanogr., 22, 155-162.

Woodgate, R. A., and K. Aagaard, 2005: Revising the Bering Strait freshwater flux into the Arctic Ocean. Geophys. Res. Lett., 32, L02602, doi:10.1029/2004GL021747.

,-- R. D. Muench, J. Gunn, G. Björk, B. Rudels, A. T. Roach, and U. Schauer, 2001: The Arctic Ocean boundary current along the Eurasian slope and the adjacent Lomonosov Ridge: Water mass properties, transports and transformations from moored instruments. Deep-Sea Res. I, 48, 1757-1792.

Yang, J., 2005: The Arctic and subarctic ocean flux of potential vorticity and the Arctic circulation. J. Phys. Oceanogr., 35, 2387-2407.

Zweng, M. M., and A. Münchow, 2006: Warming and freshening of Baffin Bay, 1916-2003. J. Geophys. Res., 111, C07016, doi:10.1029/2005JC003093. 